\title{
Workplace violence among nurses, why are we still discussing this? Literature review
}

\author{
Abigail Mitchell ${ }^{1}$, Areeg Ahmed ${ }^{2}$, Catherine Szabo ${ }^{1}$ \\ 1. D'Youville College, Buffalo, NY, USA. 2. Saskatoon, Saskatchewan, Canada.
}

Correspondence: Abigail Mitchell. Address: 320 Porter Avenue, Buffalo, NY 14201, USA. Email: mitchela@dyc.edu

Received: October 24, 2013

Accepted: January 5, $2014 \quad$ Online Published: February 13, 2014

DOI : $10.5430 /$ jnep.v4n4p147

URL: http://dx.doi.org/10.5430/jnep.v4n4p147

\begin{abstract}
Workplace violence is not new to nursing, or has it changed from generation to generation. We are still seeing intolerable situations in nursing and in most cases; we have not made changes to our organizations to eliminate our tolerance to workplace violence. It used to be called "nurses who eat their young" now we call it "horizontal workplace violence" or just "bullying". Why is this serious condition still occurring and decreasing our moral on units and even reducing our workforces?
\end{abstract}

\section{Key words}

Workplace violence, Horizontal violence, Bullying, Generation, Novice, Education

\section{Introduction}

Workplace violence is not a new occurrence in nursing. This "condition" has been around for many generations and we continue to discuss, tolerate, and make policies around this topic. The term changes, it used to call it "eating our young", then horizontal violence, then bullying, and now we use all terms interchangeably. The question we should be asking ourselves as nurses when will it stop and when we can we move forward as a profession. This article is a literature review and provides evidence based nursing.

\section{Nursing and workplace violence prevalence}

According to the Canadian Centre for Occupational Health \& Safety CCOHS (2012) ${ }^{[1]}$, workplace violence is defined as "any act in which a person is abused, threatened, intimidated or assaulted in his or her employment." This is includes threatening behaviors, verbal or written threats, verbal abuse, physical attacks such as hitting, shoving, pushing or kicking, spreading rumors, swearing, psychological trauma, property damage, harassment and bullying (para. 1). The concept of workplace violence (horizontal violence, bullying and aggression) has been discussed in nursing literature for almost two decades and over many generations. Bullying not only occurs on the playground or in various school settings, but also prevails in the workplace affecting many registered nurses nationally. Many nursing researchers maintained that inappropriate and unprofessional behaviors in nursing are common and widespread across all clinical settings and in many healthcare environments. The concept of horizontal hostility and bullying exhaust nurses energy and undermines the nursing profession ${ }^{[2]}$. 
Violence in workplace toward nurses is not new. Unfortunately, both the new and experience nurses have been victims of or witnesses to aggressive attacks ${ }^{[3]}$. Many students and new nurses are familiar with the phrase "nurses eat their young" ${ }^{[3]}$. Unfortunately, this behavior is frequently considered a "rite of passage" for the new nurse ${ }^{[3]}$. According to Fudge ${ }^{[4]}$, horizontal and vertical violence have existed in nursing for many years but are only recently beginning to be discussed and addressed. It is estimated that $50 \%$ of health care workers are physically assaulted during their professional careers and that nurses are three times more likely to experience violence than any other professional group ${ }^{[5]}$. Thomas (2010), 62\% of new nurses report having been a victim of verbal abuse ${ }^{[3]}$.

As victims of workplace violence, nursing students, new graduates, and novice faculty might remain silent out of fear and embarrassment ${ }^{[3]}$. The direct and/or indirect negative behaviors associated with workplace violence might never be known to nursing students or graduate nurses unless they are empowered with knowledge and understanding regarding how to acknowledge and report workplace violence incidents. Newly registered nurses are in high demand to assist in caring for patients at the bedside. This reduces the nursing shortage. As nurses retire, younger nurses will need to replace them. Unintentionally, nursing students, newly registered nurses and nursing faculty are contributing to the nursing shortage because of leaving the profession due to experiencing workplace violence ${ }^{[3]}$.

According to Roman ${ }^{[6]}$, the American Nurse Association states, "Nurses have the right to a safe and secure workplace in which to provide quality patient care" (p.451). The American Association cites in its position rationale that to improve the health and safety of health care workers in the workplace is a key to solving the growing nursing shortage”.

Hameric, Spross, and Hanson (2009) ${ }^{[7]}$ reported that unhealthy working environments in nursing increases the chance for nursing error and promotes moral distress, burnout, frustration, and low morale. When nurses are exposed to workplace violence, the quality of nursing care is adversely affected. Offering workplace violence continuing education to nurses and having nurses serve as positive role models for each other are critical to eliminate violence in the workplace. Healthy workplace environments begin with promoting a positive attitude among experienced and seasoned nurses toward nursing students and newly hired graduate nurses otherwise, nursing recruitment and retention is threatened, as is the future of the nursing profession ${ }^{[3]}$. To complicate the situation, nurses are choosing to leave the profession, and job key satisfaction is the key issue.

Workplace environment with 'zero-tolerance' for violence can help nurses return to caring about their profession, their patients, and each other ${ }^{[8]}$. To stop the cycle of violence in the workplace and to promote positive change, nurses must recognize instead of ignore the obvious, and must take action instead of continuing to expose newly hired graduate nurses to hostile workplace environments.

\section{Factors contributing to workplace violence in nursing}

Generational differences directly affect workplace communication and collaboration ${ }^{[9]}$. A lack of understanding regarding generational differences can impede the ability to recognize individual workplace contributions and can reduce workplace collaboration ${ }^{[9]}$. Longo et al. (2011) ${ }^{[9]}$ stated that there are four-generation levels: 1) veterans born from 1925-1945; 2) Baby Boomers Born from 1946-1964; 3) Generation Xers born from 1965-1980; and 4) Millennial born from 1980-2000. These four generation levels result in a mutigenerational workforce that increases the risk for workplace conflict because of the different values and work ethics found within each generation. Combined with challenges of new and advanced technologies and increased levels of patient acuity, generational differences in the workplace can increase stress among nurses and contribute to workplace violence.

\section{Negative effects of workplace violence}

When workplace tension is high, nursing staff are not likely to perform at their best, which may result in poor patient care practice $^{[2]}$. Safety is vital for both nurses and patients. Workplace violence can cause errors that negatively impact patients 
due to the nurse being distracted. Long and Sherman (2007) ${ }^{[10]}$ stated that workplace bullying, either in a single event or with repetitive abuse by a perpetrator; leads to nursing job performance interference or places the health and safety of the nurse at risk. Workplace violence can become part of nursing unit culture. This results in nurses who are afraid to ask for assistance from their coworkers, which increases the possibility for nursing error ${ }^{[11]}$. Longo (2010) stated that nursing managers can play a vital role in changing a negative workplace environment on their unit by examining problems with disruptive behaviors. When nursing managers identify an issue with workplace violence, they need to take appropriate action to ensure that the abuse stops that the perpetrator is held accountable, and that steps are taken to prevent negative behavior from being repeated ${ }^{[12]}$.

Most new and experienced nurses have been victims of or have been witnesses to aggressive violence in the workplace ${ }^{[3]}$. Workplace violence has numerous negative physiological, psychological, and behavioral impacts on individuals. According to Murray (2009) ${ }^{[12]}$, consequences of workplace violence can include the following: being labeled a troublemaker; fearing loss of career advancement opportunities; fearing job loss; and experiencing psychosomatic symptoms such as nervous tension, headaches, eating disorders, sleep disturbance, and onset of chronic illness. Stress factors also affect retention of the novice faculty member. Novice nurse faculty faces several new stressors when entering academia and one of them is workplace violence. New faculty are learning new roles and learning that they must have autonomy and often many "senior" faculties are behind closed doors. New faculty often will not speak out, often this can lead to being "dumped on", and with no guidance, this leads to bullying.

\section{Recommendations for change}

To prevent violence in the workplace, the Joint Commission (2010) ${ }^{[13]}$ suggested the following actions be implemented in health care settings: continuously evaluate and review environmental and administrative controls and local crime rate records and statistics; establish and evaluate violence-prevention programs on an ongoing basis; prescreen job applicants by conducting background checks and by evaluating professional competence and conduct; establish procedures for disciplining and firing employees to minimize potential for violent reaction; mandate workplace violence staff education and training that includes workplace prevention strategies and staff encouragement to report workplace violence; establish policy and procedures for responding to and reporting workplace violence; educate supervisors that all suspicious behavior and reports of workplace violence be taken seriously and thoroughly investigated; and establish counseling programs for employees who are victims of workplace violence. Continuing research is needed in exploring these suggestions by the Joint commission to see the effectiveness of each than the other.

\section{Conclusion}

Since the profession of nursing consists primarily of females, nurses are at increased risk for workplace violence ${ }^{[8]}$. According to Booth (2011) ${ }^{[14]}$, one in three nurses will leave their position due to workplace violence. Violent behaviors on nursing students and newly registered nurses can lead to high attrition rates in schools of nursing as well as decreased retention rates during the first year of professional practice ${ }^{[2]}$. It is imperative, therefore, to implement educational strategies, such as the use of educational video clips, mentoring programs and other tools to promote knowledge and understanding among newly hired graduate nurses in hospital settings about workplace violence and strategies for workplace violence prevention. Mentoring programs have also been shown to be a positive impact on developing relationships within nursing, and mentoring promotes a sense of well-being. There must be guiding principles regarding the responsibility of all leaders and employees to be accountable for workplace behavior and implement a reporting process that documents and addresses the incident. Engaging in self-awareness and reflective practice ensures that leadership styles do not support the violent behavior in the healthcare organization. Organizations must set an example by embracing transformational leadership. They need to take stand on issues, inspire challenges, listen, advice, coach, and a have a vision ${ }^{[15]}$. Workplace violence, horizontal violence, bullying, eating our young, and whatever else we call it has to 
be discussed, not tolerated, and put to rest. This topic has been a hot issue in nursing for numerous years and without making changes the topic will halt the nursing profession and we will also be discussing this topic.

\section{References}

[1] Canadian Centre for Occupational Health \& Safety. (2012). Violence in workplace. Available from: http://www.ccohs.ca/oshanswers/psychosocial/violence.html

[2] Woelfle, C. Y., \& McCaffry, R. Nurse on nurse. Nursing Forum. 2007; 42(3): 123-131. http://dx.doi.org/10.1111/j.1744-6198.2007.00076.x

[3] Thomas, C. M. Teaching nursing students and newly registered nurses strategies to deal with violent behaviors in the professional practice environment. The Journal of Continuing Education in Nursing. 2010; 41(7): 299-308. http://dx.doi.org/10.3928/00220124-20100401-09

[4] Fudge, L. Why, when we are deemed to be carers, are we so mean to our colleagues? Horizontal and vertical violence in the workplace. Canadian Operating Room Journal. 2006; 24(4): 13-16.

[5] Registered Nurses Association of Ontario. (2008). Position statement: Violence against nurses: 'Zero' tolerance for violence against nurses and nursing students. Available from: http://www.rnao.org/Page.asp?PageID=122\&ContentID=1647\&SiteNodeID=467

[6] Roman, M. Ensuring Nurses's Safety in violent workplaces. Journal of American Association of occupational Health Nurses. 2008; 56(2): 51-52.

[7] Hamric, A.B., Spross, J.A., \& Hanson, C.M. Advanced practice nursing: An integrative approach (5 ed.). St. Louis: Elsevier Saunders, 2009.

[8] Broome, B. S., \& Williams-Evans, S. Bullying in a caring professor reason, results and recommendations. Journal of Psychosocial Nursing. 2011; 49(10): 30-35.

[9] Longo, J., Dean, A., Norris, S. D., Wexner, S. W., \& Kent, L. N. It starts with a conversation: A community approach to creating healthy work environments. The Journal of Continuing Education in Nursing. 2011; 42(1): 27-35. http://dx.doi.org/10.3928/00220124-20100901-03

[10] Longo, J. Combating disruptive behaviors: Strategies to promote a healthy work environment. A Scholarly Journal of the American Nurses Association. 2010; 15(1): 1-13.

[11] Sheridan-Leos, N. Understanding lateral violence in nursing. Clinical Journal of Oncology Nursing. 2008; 12(3): 399-403. http://dx.doi.org/10.1188/08.CJON.399-403

[12] Murray, J. Workplace bullying in Nursing: A problem that can’t be ignored. Medsurg Nursing. 2009; 19(5): $273-276$.

[13] The Joint Commission. Preventing violence in the health care setting. 2010; (45). Available from: http://www.jointcommission.org/assets/1/18/SEA_45.PDF

[14] Booth, B. Alarming rise of new graduate nurse attrition. Pro Quest Nursing \& Allied Health Source. 2011: 61(1): 3.

[15] Leiper, J. Nurse against nurse: How to stop horizontal violence. Nursing. 2005; 35(3):44-48. http://dx.doi.org/10.1097/00152193-200503000-00037 